\title{
Fungal central skull-base osteomyelitis: atypical presentation and management issues
}

\author{
Sanjeev Yadav, Rajeev Kumar, Rakesh Kumar, Prem Sagar (1)
}

Otorhinolaryngology and Head and Neck Surgery, All India Institute of Medical Sciences, New Delhi, Delhi, India

\section{Correspondence to \\ Dr Rajeev Kumar;}

rajeev9843@yahoo.co.in

Accepted 2 September 2021

\section{SUMMARY}

Mucormycosis is a very commonly encountered disease in the sinonasal region in patients with diabetes and immunocompromised status specially in the northern part of the Indian continent. Due to its fulminant nature and involvement in the rhino-orbital-cerebral region, prognosis is poor even after extensive debridement and amphotericin-B therapy. We present a case with diagnosis of sarcoidosis being treated with systemic steroids who developed sudden-onset ptosis and left lateral rectus palsy. On radiological evaluation with MRI, a heterogenously peripherally enhancing lesion was seen in the nasopharynx suggestive of nasopharyngeal abscess. The patient was taken up for emergency surgery; a necrotic lesion with destruction of sphenoid bone, pterygoids and clivus was seen originating in the nasopharynx. The lesion on fungal staining came out to be broad aseptate hyphae suggestive of mucormycosis.

\section{CASE PRESENTATION}

A middle-aged woman presented to the medicine department with complaints of generalised weakness, loss of appetite, decreased sleep and occasional difficulty in breathing for 4 months. The patient was worked up and, based on haematology and radiological findings, a diagnosis of sarcoidosis was made. High Resolution Computed Tomography(HRCT) of the chest was suggestive of mediastinal, bilateral hilar and abdominal lymphadenopathy.

Cervical lymph node biopsy showed lymphoid tissue along with tiny epithelioid cell granulomas.

The patient was treated with oral prednisolone $40 \mathrm{mg}$ for 8 months. She had type 2 diabetes mellitus and hypothyroidism for 10 years, which were well controlled on oral hypoglycaemicsvildagliptin $50 \mathrm{mg}$, gliclazide $60 \mathrm{mg}$, metformin $1 \mathrm{~g}$ and thyroxine $50 \mu \mathrm{g}$. The patient presented in emergency with left eye ptosis, diplopia in the left lateral gaze and decreased sensation over the left cheek for the last 1 month. Gadolinium contrastenhanced MRI showed heterogenously enhancing hyperintense lesion in the left posterior nasopharyngeal wall extending into the paranasal fat, prevertebral region with postcontrast heterogenous peripheral enhancement (figure 1). There was destruction of the left pterygoid plate, the floor of the middle cranial fossa with involvement of the left carotid canal. Positron Emission TomographyPET-CT showed necrotic lesion (SUV- 5.2) in the nasopharyngeal wall with involvement of fossa of Rosenmüller and the left carotid canal (figure 2). Multiple supraclavicular, mediastinal, paratracheal, precarinal and bilateral hilar lymph nodes were also noted (SUV 3.9). Before taking up for surgical debridement, CT angiography was done to look for internal carotid artery (ICA) involvement. CT angiography showed complete thrombosis of the left ICA and involvement directly in the necrotic lesion (figure 3). Post-COVID-19 testing, emergency endoscopic debridement was done, which showed a necrotic lesion in the nasopharynx with black crusts destroying sphenoid bone, pterygoids and prevertebral body (figure 4). $\mathrm{KOH}$ mount showed broad aseptate hyphae suggestive of mucormycosis. The patient was started on liposomal amphotericin-B, and systemic steroid administration was stopped. The patient was started on azathioprine for sarcoidosis. However, the patient had no neurological deficit and had good cross circulation on angiography. The patient had progressive leucopenia (TLC $=1100 / \mathrm{microL}$ ) during the treatment course. Medicine consultation was done and it was presumed to be drug induced. Azathioprine was stopped and the patient was continued on amphotericin-B. Bone marrow biopsy was done for establishing diagnosis and showed megaloblastic picture

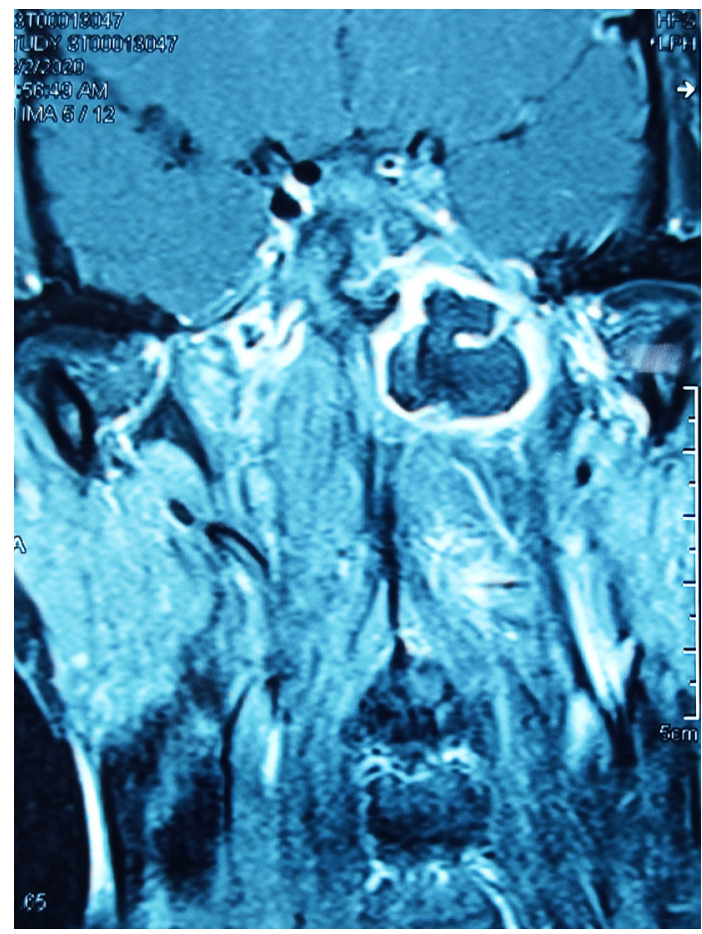

Figure 1 Gadolinium-enhanced MRI of the head and neck showed nasopharyngeal abscess with heterogenous enhancement in the left cavernous sinus and loss of T2 flow voids in the left internal carotid artery. 


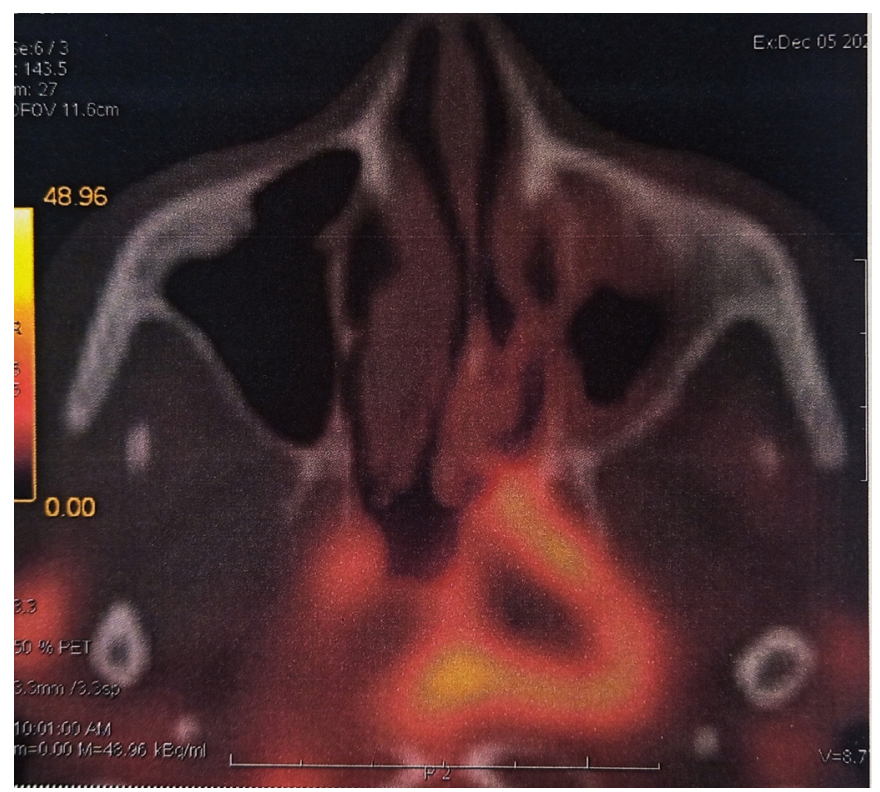

Figure 2 PET-CT scan showed proliferative necrotic lesion in the left nasopharynx (SUV max 5.2) with involvement of the left fossa of Rosenmüller, left carotid canal, pterygoid plates, basisphenoid and odontoid process.

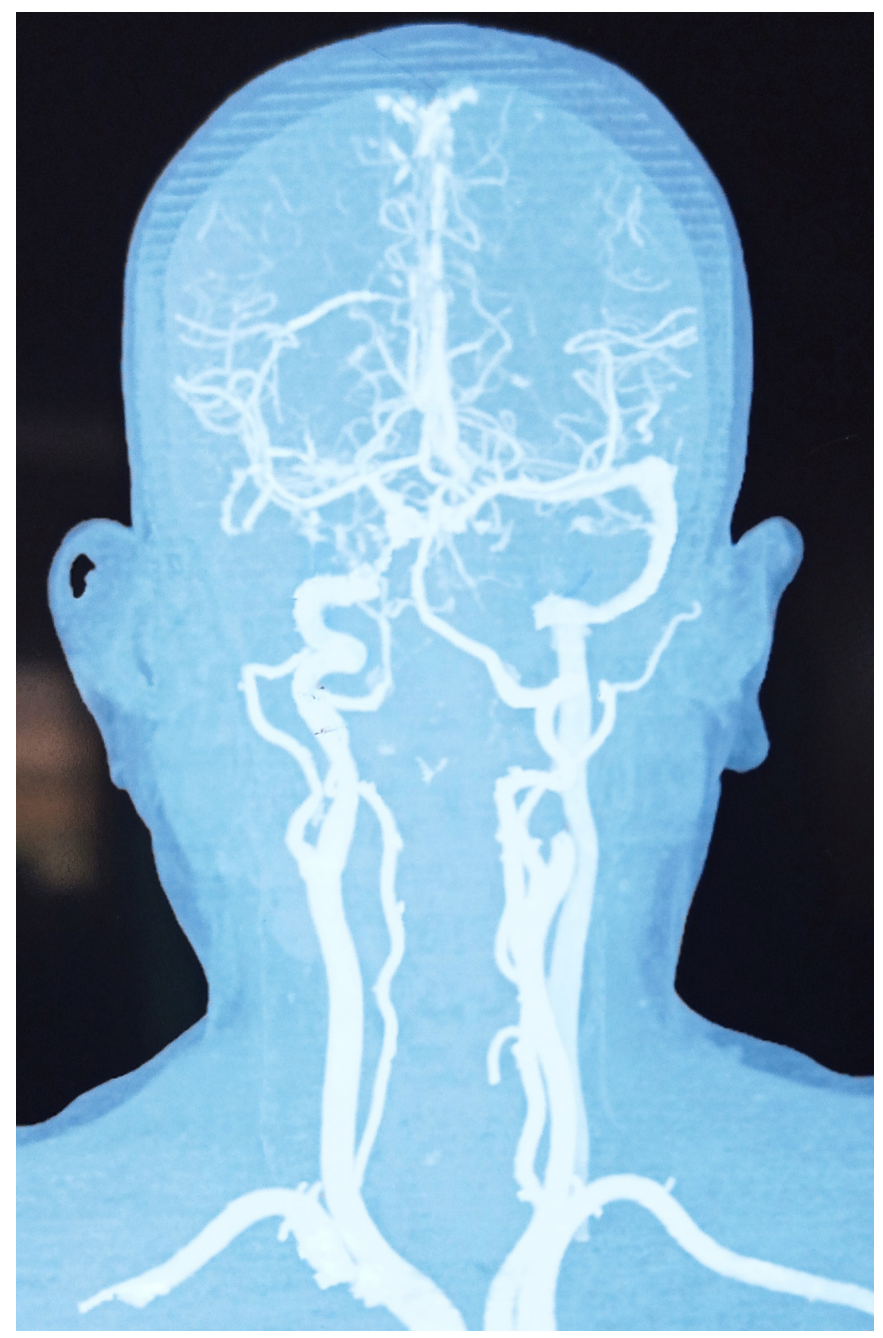

Figure $3 \mathrm{CT}$ angiography shows thrombosis of the left cavernous, petrous and upper cervical segments of the internal carotid artery.

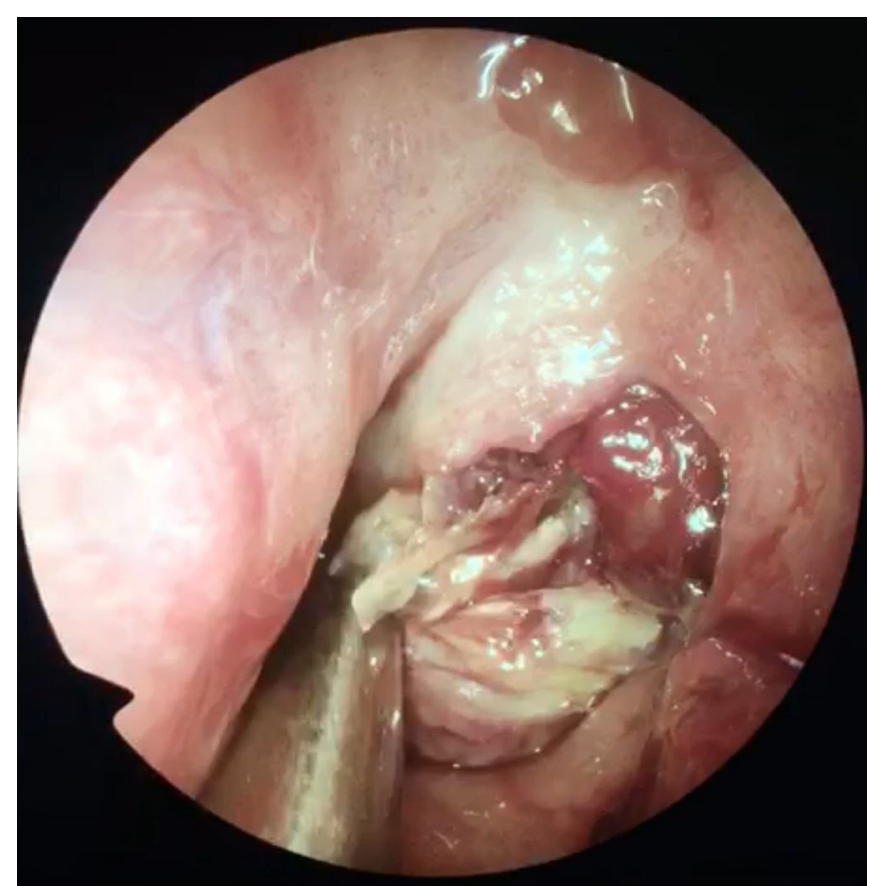

Figure 4 Endoscopic view of necrotic tissue in the nasopharynx and pterygoid region during endoscopic debridement of disease.

only. However, leucopenia did not improve and again medicine referral was done. It was advised to stop amphotericin-B and give granulocyte-macrophage colony-stimulating factor (GM-CSF) in view of persistent leucopenia. The patient was supplemented with three doses of GM-CSF (300 mcg once day subcutaneously) and was started on syrup posaconazole ( $5 \mathrm{~mL}$ twice a day). Leucocyte count improved to $9500 /$ microL. The patient was given a cumulative dose of $4 \mathrm{~g}$ liposomal amphotericin-B before starting syrup posaconazole. Ptosis and gaze gradually improved in the left eye. There were no complaints of decreased vision or diplopia, and the patient was discharged in haemodynamically stable condition on syrup posaconazole.

\section{INVESTIGATIONS}

Haemoglobin-8.1 g/dL

Platelet: $120 \times 10^{3} / \mathrm{microL}$

Ionised parathyroid hormone $(\mathrm{PTH})=9.93 \mathrm{pg} / \mathrm{mL}$

Ionised calcium $=1.63 \mathrm{~mm} / \mathrm{L}$

TLC $=3940 / \mathrm{microL}$

$\mathrm{ACE}=42.9 \mathrm{U} / \mathrm{L}$

\section{DIFFERENTIAL DIAGNOSIS}

The patient was first diagnosed to be a case of sarcoidosis with comorbidities of diabetes and hypothyroidism. During systemic corticosteroid treatment, the patient developed left eye diplopia (left lateral rectus palsy). Consequently, contrast enhanced MRI of the head and neck region was done, which showed nasopharyngeal abscess and PET scan was suggestive of increased uptake suggestive of malignancy with involvement of the left cavernous ICA. The patient did not have any neurological deficit. On diagnostic nasal endoscopy, necrotic bones and unhealthy tissue were seen in nasopharynx, which came positive for aseptate hyphae, suggesting mucormycosis on $\mathrm{KOH}$ smear. 


\section{TREATMENT}

The patient was managed on insulin to control increase blood sugars and was continued on thyronorm $25 \mathrm{mg}$ for hypothyroidism. Postemergency debridement, the patient was started on injection liposomal amphotericin-B in optimal doses until cumulative dose of $4 \mathrm{~g}$. The patient was continued on azathioprine, which is a second-line drug for sarcoidosis. Subcutaneous enoxaparin was also administered in view of ICA thrombosis with monitoring of aPTT. In view of progressive leucopenia, azathioprine and amphotericin administration was stopped and supplementation with three doses of GM-CSF was done. The patient was discharged on syrup posaconazole $5 \mathrm{~mL}$ BD.

\section{OUTCOME AND FOLLOW-UP}

The patient was admitted for 28 days and in between was consulted with haematology, neurology, endocrinology and medicine departments for the treatment plan. The patient was continued on syrup posaconazole and was advised monthly follow-up.

\section{DISCUSSION}

Sarcoidosis is a multisystem disease characterised by formation of non-caseating granulomas in affected organs. It generally presents clinically and radiologically with respiratory symptoms, blurred vision, bilateral hilar lymphadenopathy and erythema nodosum. Hypercalcaemia, hypercalciuria, hypervitaminosis $\mathrm{D}$ and decreased ionised PTH are also seen in patients with sarcoidosis. ${ }^{1}$ Only $60 \%$ of cases show elevated levels of ACE. ${ }^{2}$ Recent guidelines suggest performing a peripheral lymph node biopsy when such an approach is easily pursuable. Non-caseating granulomas are seen in histopathology in most cases. ${ }^{3}$ In sarcoidosis, corticosteroids are the mainstay of therapy. Our patient had similar presenting complaints and was managed on the same line of treatment. Long-term steroid therapy with diabetes might have been a precursor for development of nasopharyngeal mucor in our patient.

The incidence of nasal and sinus diseases in cases of sarcoidosis is $<1 \%$. Mostly described reports suggest dry, friable mucosal lesions generally involving the septum and inferior turbinates. ${ }^{4}$

Waness et al identified sarcoidosis as one of the predisposing factors in the development of mucormycosis, though nothing much was said about the treatment of the condition in the same. ${ }^{5}$

The prevalence of mucormycosis is very high in India (14 per lakh) as compared with other highly populated countries. Its most common cause is uncontrolled diabetes mellitus and immunocompromised states. ${ }^{5}$ The clinical signs which are termed 'red flags' are cranial nerve palsies, diplopia, proptosis, sinus pain, swelling in the periorbital region, orbital apex syndrome and ulcer of the palate. ${ }^{6}$

Nasopharyngeal mucormycosis osteitis was described in English literature way back in 1980. The lesion appeared to start in the nasopharyngeal area, causing ischaemic osteitis of skull base. Multiple cranial nerves from V to XII were believed to be involved extracranially by direct extension or compression secondary to oedema in surrounding tissues. ${ }^{7}$ A similar osteitic picture along with palsy of opthalmic, maxillary and abducens nerve was seen in our case.

Mucormycosis is angioinvasive and can cause thrombosis within large venous and arterial channels. Vasculopathy of such kind intracranially can result in stroke. Sometimes the presence of good collateral blood supply via circle of Willis protects against the occurrence of cerebral ischaemia. ${ }^{8}$ Complete thrombosis of ICA is rare but is reported in literature. The mucor thrombus can extend retrogradely from the smaller ophthalmic arteries to involve ICA in a short time span, which can additionally form infarcts. ${ }^{9}$

In our patient, there was evidence of complete thrombosis of cavernous and petrous segment of the left ICA. Despite that there were no clinical or radiological signs of stroke due to good collaterals as evident from angiography.

Successful management of this invasive fulminant fungal sinusitis involves correction of predisposing factors, early administration of antifungal agents and debridement of infected tissues. ${ }^{6}$

European Confederation of Medical Mycology initiated 'One World One Guideline' for treatment in mucormycosis. It strongly recommended administration of high-dose liposomal amphotericin-B and surgical debridement as first-line treatment. Intravenous isavuconazole and syrup posaconazole were also recommended with moderate strength. ${ }^{10}$ Our patient was also treated on the same guidelines and was discharged in satisfactory condition.

\section{Patient's perspective}

I had problems of sugar and low thyroid hormone since 10 years for which I was taking medicine from private hospitals. Last year I started developing gradual weakness and shortness of breath for which I showed in multiple departments of AIIMS, Delhi, and diagnosed to be a case of sarcoidosis and got treated for it. I was started on oral steroid therapy due to which my sugar levels got deranged. Then after 4 months I noticed that I have double vision in my left eye. I consulted an ENT doctor and MRI was done. Emergency surgery was performed and a diagnosis fulminant fungal infection was made after surgery. I was told about that and started on antifungal medications. My vision gradually started improving and there is no double vision now. I am feeling better than previous and I have been discharged on antifungal medication and hope to get completely cured early.

\section{Learning points}

- Mucormycosis can occur as a complication in sarcoidosis due to prolonged use of systemic steroids in already immunocompromised patients such as those with diabetes.

- Always keep mucormycosis as a differential in cavernous syndrome in patients with diabetes or immunocompromised states.

- Early debridement and optimal dose liposomal amphotericin administration should always be the first line of treatment in mucormycosis.

- Aggressive control of underlying conditions and biochemical parameters are of utmost importance in limiting the spread of disease.

- Keep a vigilant eye on leucocyte count along with serum electrolytes and urea, creatinine during amphotericin administration.

Contributors SY, the primary author of this case, has drafted the case report and followed up the case in ward. RajK is the corresponding author and primary surgeon in the treatment of the patient. RakK and PS helped in the review of literature and in refining the case report and review.

Funding The authors have not declared a specific grant for this research from any funding agency in the public, commercial or not-for-profit sectors.

Competing interests None declared.

Patient consent for publication Obtained. 
Provenance and peer review Not commissioned; externally peer reviewed.

\section{ORCID iD}

Prem Sagar http://orcid.org/0000-0001-5590-9279

\section{REFERENCES}

1 Spagnolo P, du Bois RM. Genetics of sarcoidosis. Clin Dermatol 2007;25:242-9.

2 Baughman RP, Teirstein AS, Judson MA. Clinical characteristics of patients in a case control study of sarcoidosis. Am J Respir Crit Care Med 1885;2001:15.

3 Yanardag H, Caner M, Papila I, et al. Diagnostic value of peripheral lymph node biopsy in sarcoidosis: a report of 67 cases. Can Respir J 2007:14:209-11.

4 Zeitlin JF, Tami TA, Baughman R, et al. Nasal and sinus manifestations of sarcoidosis. Am J Rhinol 2000;14:157-62.

5 Waness A, Dawsari GA, Al Jahdali H. The rise of an opportunistic infection called "Invasive Zygomycosis". J Glob Infect Dis 2009;1:131.
6 Skiada A, Lass-Floerl C, Klimko N, et al. Challenges in the diagnosis and treatment of mucormycosis. Med Mycol 2018;56:S93-101.

7 Bahna MS, Ward PH, Konrad HR. Nasopharyngeal mucormycotic osteitis: a new syndrome characterized by initial presentation of multiple cranial nerve palsies. Otolaryngol Head Neck Surg 1980;88:146-53.

8 Al-Otaibi F, Albloushi M, Alhindi H, et al. Carotid artery occlusion by rhinoorbitocerebral mucormycosis. Case Rep Surg 2012;2012:1-4.

9 Patil A, Mohanty HS, Kumar S. Angioinvasive rhinocerebral mucormycosis with complete unilateral thrombosis of internal carotid artery—case report and review of literature. BJR| case reports 2016;1:20150448.

10 Cornely OA, Alastruey-Izquierdo A, Arenz D, et al. Global guideline for the diagnosis and management of mucormycosis: an initiative of the European Confederation of medical mycology in cooperation with the mycoses Study Group education and research Consortium. Lancet Infect Dis 2019;19:e405-21.

Copyright 2021 BMJ Publishing Group. All rights reserved. For permission to reuse any of this content visit https://www.bmj.com/company/products-services/rights-and-licensing/permissions/

BMJ Case Report Fellows may re-use this article for personal use and teaching without any further permission.

Become a Fellow of BMJ Case Reports today and you can:

- Submit as many cases as you like

- Enjoy fast sympathetic peer review and rapid publication of accepted articles

- Access all the published articles

- Re-use any of the published material for personal use and teaching without further permission

\section{Customer Service}

If you have any further queries about your subscription, please contact our customer services team on +44 (0) 2071111105 or via email at support@bmj.com.

Visit casereports.bmj.com for more articles like this and to become a Fellow 